\title{
Analysis of Administrative Culture Research from the Aspect of Bibliometrics
}

\author{
Sun Zhuo-hua ${ }^{1, a}$, Chen Jing ${ }^{2, b}$,Li Qiang-Nan ${ }^{3, c}$ \\ 1,3 law school Shandong University (Weihai), Weihai China, 264209 \\ ${ }^{2}$ China University of Political Science and Law, Beijing China, 100088 \\ abigsun68@sina.com, b1007730145@qq.com, '836656924@qq.com
}

Keywords: Administrative Culture $\mathrm{H}$-index Total Cites

\begin{abstract}
Using the key words related to administrative culture, we retrieved the articles which were published in the period from 1990 to December 2012 in the CNKI database. Then through comparing the data from the aspect of number of post, institution and periodical, this article teased out the research status of administrative culture in recent twenty years and got more objective conclusion in order to provide inspiration for the research on how to improve the administrative culture.
\end{abstract}

\section{Introduction}

Using the map of scientific knowledge and visualization technology to draw the research results of administrative study in the recent twenty-two years, this article could do the academic positioning description and analysis of the administrative culture research focus directly and visually from the aspect of quantification and visualization in order to find the characteristics and lack of study and provide a more reasonable theoretical guidance for administrative reform and development.

\section{Literature Data Statistics}

\section{A. The Definition of Administrative Culture}

Defining the concept of administrative culture is the premise of this study. As the study of administrative culture in contemporary China has been for just twenty years, the definition of related concepts was differ and controversial, and the border of study is not clear. In general, the definition of administrative culture can be divided into three categories: broad sense, medium sense and narrow sense.

The broad sense of administrative culture is based on the aspect of cultural perspective. A general sense of cultural definition includes three levels: material culture, system culture and spirit culture. On the basis of such cognitive pattern, some researchers point out that the connotation of administrative culture which is influenced by objective and subjective factors should includes administrative material culture, administrative system culture and administrative spirit culture. Administrative culture is an unique culture pattern which integrates the physical facilities and institutional norms of administrative organizations and the common thoughts, values, thinking pattern, psychological state, behavior standard and lifestyle of administrative staff.

Because the conception of this article is to summarize and analyze the research status of administrative culture of China in recent 20 years, so we choose the broad sense.

\section{B. Number of Published Papers over the Years}

The data used in this research is derived from Chinese literature data pool (CNKI), the retrieval time rages from 1990 to December 31, 2012. In the database, using administrative culture and related words extracted from broad sense such as administrative consciousness, administrative thoughts, administrative ethics, administrative ideas, administrative psychology, administrative system, administrative organizations and administrative regulations as search term, we got 8628 essays in total, 2313 of which were published in Peking University core periodical and 1652 of which were 
published in CSSCI. By removing contributions, solicitation, reviews, meeting notice, and a draft of multiple, we got 7357 essays eventually. The trend of the number of published papers over the years is shown in Fig.1.

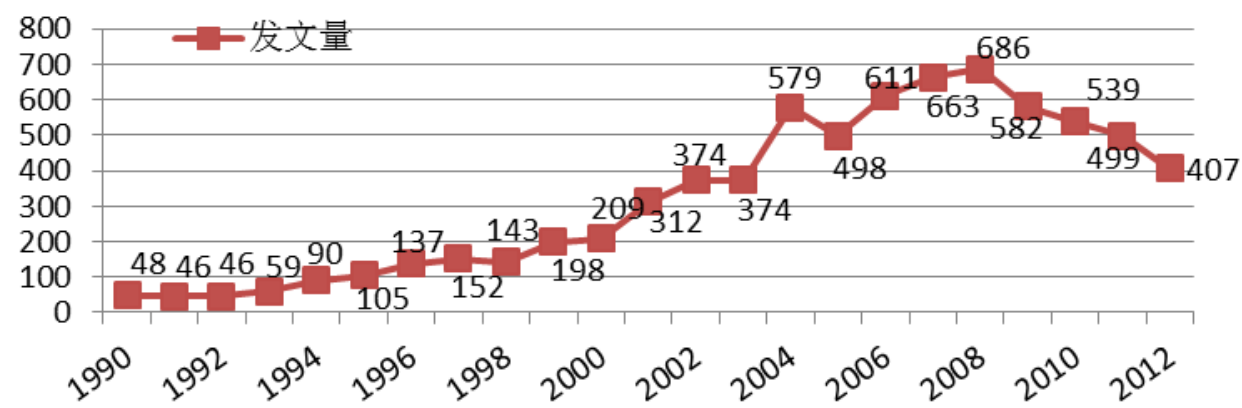

Fig.1 chart of number of published papers related to administrative culture over the years from 1999 to 2012

From the chart, we can find that the number of published papers each year had been increasing until the year of 2009 except for 1998 and 2005, and then the number began to decrease while the declines were modest. Through the data retrieval, we can find that the scholars who published more papers reduced their related articles after 2009, especially after 2011. This indicates that the focus of administrative culture research has transferred.

\section{Comparative Analysis of Bibliometrics Indicators}

Using methods and indicators of literature metrology, this paper analyzed the data and carried on comparison on different indicators, then summed up some questions about administrative culture research.

\section{A. Comparison of Evaluation Index of Prolific Authors}

The data showed that there are more than fifty scholars who published more than 5 papers. The top 10 are showed in Table 1. Many universities and research institutions use the number of published paper as the main index for scientific research evaluation, while the author think that the index is biased. Using the top 10 prolific authors as analysis object, this paper figured out the total citations, the average cited frequency, the highest cited frequency and the $\mathrm{H}$ Index(H Index is a mixture of quantitative indicators used to assess the quantity of academic output and the level of academic output).All of these are showed in Table 1. Through the comparison, we can find:

(1) The number of published papers, the total citations, the average cited frequency, the highest cited frequency and the $\mathrm{H}$ Index of some authors such as Zhang Kangzhi from school of public administration, renmin university of China ${ }^{[1]}$, Liu Zuyun from nanjing agricultural university ${ }^{[2]}$, Wang Wei from China national school of administration ${ }^{[3]}$, Jing Taijun from Nanjing normal university are all high. Not only their number of published papers is at the top, but also the cited frequency and $\mathrm{H}$ index is second to none. This indicates that they are core and leaders in the field of administrative culture research who has the very good demonstration effect and strong influence in the field of academic research.

(2) The number of published papers of some authors including Lu Zhizeng from Guilin institute of technology, BaoXingRong from Yunnan administration college and so on is high, while the highest cited frequency, the cited frequency, $\mathrm{H}$ index, average citation rates of these authors are low. Although they are in the list of the top 10 prolific authors, the $\mathrm{H}$ index and the citation rates are low. This indicates that although they have done much research, their demonstration effect and influence are relatively weak. 
Tab.1 The evaluation index of the top 10 prolific authors

\begin{tabular}{|c|c|c|c|c|c|}
\hline Author & $\begin{array}{c}\text { Number of } \\
\text { published papers }\end{array}$ & $\begin{array}{c}\text { Total } \\
\text { Citations }\end{array}$ & $\begin{array}{c}\text { The average } \\
\text { cited frequency }\end{array}$ & $\begin{array}{c}\text { The highest } \\
\text { cited frequency }\end{array}$ & H Index \\
\hline Zhang Kangzhi & 25 & 497 & 19.88 & 104 & 11 \\
\hline Liu Zuyun & 25 & 254 & 10.16 & 84 & 9 \\
\hline Wang Wei & 25 & 225 & 9 & 42 & 10 \\
\hline Lu Zhizeng & 14 & 57 & 4.07 & 33 & 3 \\
\hline Yan Jiahua & 13 & 85 & 6.54 & 17 & 7 \\
\hline He Ying & 13 & 92 & 7.07 & 62 & 7 \\
\hline Jin Taijun & 11 & 198 & 18 & 44 & 4 \\
\hline Li Ping & 10 & 79 & 7.9 & 15 & 4 \\
\hline Luo Jianwen & 10 & 52 & 5.2 & 9 & 2 \\
\hline Bao Xingrong & 10 & 24 & 2.4 & 18 & 6 \\
\hline
\end{tabular}

(3) There are some authors, such as Yan Jiahua from Xiangtan university ${ }^{[4]}$, and He Ying from Heilongjiang university ${ }^{[5]}$, who have a high number of published papers and a high $\mathrm{H}$ index but low total citation. Although the cited frequency of their papers is low, but in contrast the $\mathrm{H}$ index was relatively high. On the basis of science evaluation meaning of the $\mathrm{H}$ index, we can say that their influence in the administrative culture research is strong.

(4) While some authors are out of the list of top 10, but the cited frequency and $\mathrm{H}$ index of their papers is high. Such scholars include Zhang Chengfu from renmin university of China, and Tang Jianyun from Xiangtan University. This indicates that the impact of these scholars in the field of administrative culture academic is also big.

To sum up, we should not evaluate the academic level and influence of an academic researcher just from a certain evaluation index. Instead, we should integrate several scientific and reasonable evaluation index, enactment them right weight and try to evaluate a researcher's scientific research level and influence on the whole. By doing this, we can minimize the bias of the evaluation, and make an accurate, scientific and reasonable evaluation of workers engaged in academic research.

\section{B. The comparison of the evaluation index of the top 10 scientific research institutions}

The retrieval results show that there are more than 50 scientific research institutions whose number of published papers are more than 30, while only 26 whose number are more than 50 and only 4 whose number are more than 100. In this paper, through calculating and comparing the number of each evaluation index of the top 10 scientific research institutions, we can find some problems and enlightenment concerned with the evaluation index of scientific research institutions.

Tab. 2 The evaluation index of the top 10scientific research institution

\begin{tabular}{|l|c|c|c|c|c|}
\hline Name of Organization & $\begin{array}{c}\text { Number of } \\
\text { published } \\
\text { papers }\end{array}$ & $\begin{array}{c}\text { Total } \\
\text { Citations }\end{array}$ & $\begin{array}{c}\text { The average cited } \\
\text { frequency }\end{array}$ & $\begin{array}{c}\text { The highest } \\
\text { cited frequency }\end{array}$ & $\begin{array}{c}\mathrm{H} \\
\text { Index }\end{array}$ \\
\hline Renmin University of China & 179 & 1828 & 10.21 & 104 & 22 \\
\hline Wuhan University & 129 & 872 & 6.76 & 90 & 15 \\
\hline Xiangtan University & 127 & 659 & 5.19 & 50 & 13 \\
\hline Fujian Normal University & 103 & 356 & 3.46 & 59 & 10 \\
\hline Nanjing University & 98 & 618 & 6.31 & 149 & 11 \\
\hline Sichuan University & 96 & 205 & 2.13 & 26 & 8 \\
\hline Peking University & 93 & 1256 & 13.51 & 316 & 16 \\
\hline $\begin{array}{l}\text { Central China Normal } \\
\text { University }\end{array}$ & 89 & 590 & 6.63 & 92 & 12 \\
\hline Beijing Normal University & 81 & 404 & 4.99 & & 95 \\
\hline national school of administration & 77 & 891 & 11.57 & 80 & 11 \\
\hline
\end{tabular}

(1) The discretion of the $\mathrm{H}$ index is proportional to the number of published papers, and the cited frequency. Xiangtan universities, Wuhan University and Renmin university of China are the top 3 whose number of published papers is high, while the cited frequency and $\mathrm{H}$ index is also high. This not only showes that the scientific research institution have a high yield in academic research papers 
in the field of administrative culture, but also suggests that these research institutions have a strong academic contribution and influence in the field of administrative culture.

(2) There are some institutions whose number of published papers is low while whose $\mathrm{H}$-index is a bit higher. The number of published papers of Beijing university,and the national school of administration ranks seventh and tenth respectively, but the $\mathrm{H}$ index of Beijing university ranks second $(\mathrm{H}=16)$, and the $\mathrm{H}$ index of National school of administration along with Wuhan university ranks third $(\mathrm{H}=15)$.For Zhongshan University, although the number is 15, but the $\mathrm{H}$ index ranks the fourth $(\mathrm{H}=14)$. The number of published papers of Fudan University, and the East China Normal University ranks 12 th and $18^{\text {th }}$ respectively, but their $\mathrm{H}$ index ranks fifth $(\mathrm{H}=13)$ along with Xiangtan University. Based on the definition of $\mathrm{H}$ index, this shows that although these research institutions do not post so many papers, its power or influence in the field of administrative cultural study is at the forefront. These institutions should be paid much attention, and continue to make their contribution to the research.

\section{The comparison of evaluation index between the top 10 academic journals}

The retrieval data shows that there are 15 journals that published more than 40 papers in administrative culture research field, while only five journals published more than 100 papers. The cited frequency and $\mathrm{H}$ index of the five journals in addition to the "law and society" are also high. In addition, although Guangdong administrative college journals that ranked sixth only published 63 academic papers in the field of administrative culture, but its cited frequency and $\mathrm{H}$ index are higher compared with those of other journals, and rank only second to China's administrative management, administration and law, Administrative Tribuneand journal of Yunnan Administration College.

Tab. 3 The evaluation index of the top 10 journals

\begin{tabular}{|c|c|c|c|c|c|}
\hline Journal Name & $\begin{array}{c}\text { Number of } \\
\text { published } \\
\text { papers }\end{array}$ & $\begin{array}{c}\text { Total } \\
\text { Citations }\end{array}$ & $\begin{array}{c}\text { The average } \\
\text { cited frequency }\end{array}$ & $\begin{array}{c}\text { The highest } \\
\text { cited } \\
\text { frequency }\end{array}$ & $\begin{array}{c}\text { H } \\
\text { Index }\end{array}$ \\
\hline Chinese Public Administration & 196 & 2134 & 10.89 & 169 & 21 \\
\hline Public Administration \& Law & 168 & 778 & 4.63 & 53 & 13 \\
\hline Administrative Tribune & 150 & 948 & 6.32 & 62 & 15 \\
\hline Legal System and Society & 129 & 155 & 1.2 & 12 & 5 \\
\hline $\begin{array}{c}\text { Journal of Yunnan administration } \\
\text { college }\end{array}$ & 114 & 661 & 5.80 & 41 & 14 \\
\hline $\begin{array}{c}\text { Journal of Guangdong institute of } \\
\text { administrative }\end{array}$ & 63 & 317 & 5.03 & 50 & 10 \\
\hline $\begin{array}{c}\text { Journal of Sichuan } \\
\text { Administration College }\end{array}$ & 63 & 226 & 3.59 & 48 & 7 \\
\hline $\begin{array}{c}\text { Journal of Liaoning } \\
\text { Administration College }\end{array}$ & 58 & 112 & 1.93 & 11 & 6 \\
\hline Manager & 52 & 18 & 0.35 & & 3 \\
\hline $\begin{array}{c}\text { Chengdu university } \\
\text { administration }\end{array}$ & 51 & 177 & 3.47 & 30 & 7 \\
\hline
\end{tabular}

\section{The results and discussion}

$\mathrm{H}$ index is an indicator used to evaluate scientist's academic influence in a certain field, which can explain a certain problem in the field of the academic research while has a lot of shortcomings. So it can be used to evaluate the influence of research institutions and the academic journals. 


\section{A. Theoretical research, basic research and literature review papers has a great influence on study}

Comparing the number of published papers and cited frequency of the scientific research institutions, and academic journals, we can find the paper with a higher cited frequency all belong to papers about theoretical research, basic research, literature review and other academic papers. These papers have very good demonstration effect and high reference value for the subsequent research in the field. The paper with a lower cited frequency mostly belongs to applied, seasonal strong paper. They don't have a good reference value for the follow-up study in this field. The publication of the paper also means the end of study, and this kind of paper will be forgotten as time goes on. Even the time when papers were published was much earlier, the cited frequency is also very low, even zero cited. There is another case that although the papers are clinical and basic research papers, the cite frequency is low for the time that they were published is late and they haven't shown high reference values. As time goes on the cited frequency will be increasing. And the extend of increase will depends on whether the theoretical and basic property of papers are strong or not.

\section{$B$. The author with a higher $H$ index generally has more influence in the study of administrative culture.}

Through the comparison among the $\mathrm{H}$ index of the authors, scientific research institutions and academic journals, we find that the author with a higher $\mathrm{H}$ index has been sticking to the academic research in the field of administrative culture, and their research contents are theoretical, fundamental and continuous. Higher $\mathrm{H}$ index means that not only the authors have published relatively more papers, but also the cited frequency is high and steady. Zhang Kangzhi and Yan Jiahua are good examples. In contrary, although the citations of some papers of some authors are high, the $\mathrm{H}$ index of these authors is low, that is due to their follow-up study is not strong, or the jumpy of the cited frequency is bigger

\section{Scholars with big academic influence mostly come from the scientific research institution with a high $H$ index in certain field}

Through the comparison of the $\mathrm{H}$ index of scientific research institution, we find that the research institutions with a higher $\mathrm{H}$ index in a certain field always have influential experts and scholars. The reason may be that the researches of scientific research institution in the field ware always done through a powerful scientific research team rather than just a well-known scholar alone. And a research institution can form a scientific research team that can do continuous study by doing this, and then expand its influence in academic study.

Through the comparison of the $\mathrm{H}$ index, we also find that except for the high number of published papers, the $\mathrm{H}$ index of an academic journal also depends on the academic influence in certain field of the authors who published papers on it and whether the paper is about basic study or review study. This is also a reason to explain the quirk in domestic academic publishing.

\section{References}

[1]Zhang Kang-zhi. The Institutional Guarantee to Administrative Morality. ZheJiang Social Sciences,1998 (4): 63-68.

[2] Liu Zu-yun, GAO Zhen-yang. Construction of Administrative Ethics in Contemporary China: Background, Environment and Situation. Journal of Nanjing Agricultural University( Social Sciences Edition), 2010 (1) : 69-76.

[3] Wang Wei. Cultural Consciousness of Chinese Public Administration Ethics. Morality and Civilization, 2003 (5) : 4-11.

[4] Yan Jia-hua. Explore Administrative Philosophy from Perspectives of Administrative Though. Chinese Public Administration, 2007 ( 7) : 71-74.

[5] He Ying. Views on Administrative Philosophy. Chinese Public Administration, 2008 (6) : 63-67. 